UCRI- 99626

PREPRINT

\title{
NEUTRONICS ANALYSIS OF THE LABORATORY MICROFUSION FACILITY
}

\author{
M. T. Tobin \\ M. S. Singh \\ H. R. Meler
}

This paper was prepared for submittal to the Eighth Toplcal Heeting on the Technology of Fusion Energy

October 9-13, 1988

sait Lake city, Utah

September 19, 1988

This is a preprint of a paper intended for publication in a joumal or procedinga Since changes may be made before publication, this preprint is mide avaliable with the understanding that it will not be cited or reproduced withoat the permisoion of the author. 


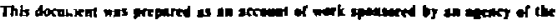

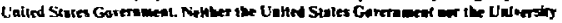

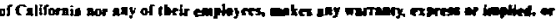

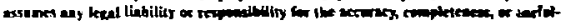

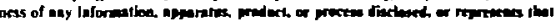

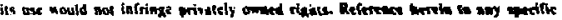

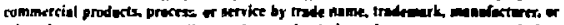

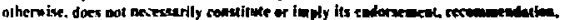

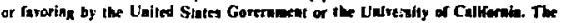

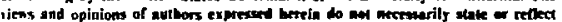

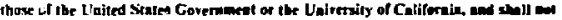

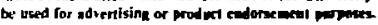


VCRL- -99626

DE89 004014

NEUTRONICS ANALYSIS OF THE LABORATORY MICROFUSION FACILITY

M. T. Tobin and H. S. Singh Lawrence Livermore Natioild I Laboratory P.0. Box 5508, L-481

Livermore, CA 94550

(415) 423-1168
W. R. Meier

H. J. Schafer Associates

6140 Stoneridge Mall Road, Suite 385

Pleasanton, CA 94556

(415) $463-1108$

\section{ABSTRACT}

The radiological safety hazards of the experimental area (EA) for the proposed Inertial confinement Fusion (ICF) Laboratory Hicrofusion Facility (LMF) have been examined. The EA includes those structures required to estabitsh the proper pre-shot environment. point the beams, contain the pellet yield, and measure many different facets of the experiments. The radiation dose rates fror neutron activation of representative target chamber materials, the laser beam tubes and the argon gas they contain, the alr surrounding the chamber, and the concrete walls of the experimental area are given. Combining these results with the allowable dose rates for workers, we show how radiological considerations affect access to the inside of the target chamber and to the diagnostic platform area located outside the chamber. Waste disposal and triciun containment issues are summarized. Other neutronics issues. such as radiation damage to the final optics and neutron heating of materials placed close to the target, are dlso addressed.

\section{INTRODUCTION}

The Laboratory Microfusion Facility will be designed to contain target fusion reaction ylelds up to a nominal $1000 \mathrm{MJ}$. This corresponds to the production of $3.6 \times$ 1020 D-T neutrons per shot peaked at

$14.1 \mathrm{MeV}$. The radiological hazards, resulting from this burst of high energy neutrons and from the surrounding materials they activat? present a significant challenge to the facility desiyners. Neutrons must be moderated and absorbed, along with the secondary and decay gamma rays. In such a manner that the facility meets the U.S. Department of Energy (DOE) radiological siting requi rements, 3 the International Commission on Radiological Protection (ICRP) (and DOE) public dose ilimits, 2 the DOE occupational dose $13 \mathrm{mits} .3$ and the more stringent LLNL as low as reasonably achievable (ALARA) guidelines. 4
The primary goal of the facility is to conduct some 1400 target experiments over a five-yodr period to demonstrate high gain in the laboratory. Projected yfelds for these experiments range from ( $10 \mathrm{HJ}$ to $-1000 \mathrm{HJ}$. After high gain has been achieved, target yields above $100 \mathrm{WJ}$ will be used to conduct weapons physics and weapons effects experiments. High gain experinents are expected to be conducted once per week. This will extend the facility lifetime to as much as 30 years.

He have set two design goais that mintmize the affect of radiation hazards on the operation of the facility. The first is that LHF workers will have access to the diagnostic platforms outside the target chamber within 24 hours after a high-yleid shot. This is required to retrieve data and set up for the next shot. Although it is posslble that routine interior chamber operations wil be done remotely, workers may occastonally require access to the inside of the chamber for nonroutine operations and matntenance. Therefore. the second design goal is that workers can safeiy enter the chamber for a short time 7 days after a high-yield shot. As quantitative measures of these two design goals, we have established dose ra:e ligits of 2 mrem/hr outside the chamber 24 hours after a shot and $100 \mathrm{mrem} / \mathrm{hr}$ inside the chamber 7 days after a shot.

Several conceptual designs are currently being proposed for the LMF target chamber. All the designs include an inner first wall (a luminum, carbon. Kevlar epoxy, or fiberglass) that is protected from $x$ rays vith some other material (frozen nitrogen, a layer of ice or porous alumina, or a carbon carpet). a neutron moderator and absorber (zater or borated graphite), and an outer structural wall (aluminum or steel). In this paper, we describe the results for a representative target chamber that consists of an inner 4-im-thick a lunitnum wall. a 2-m-thick region of water, and an outer 4 -cm-thick structural wall 
also made of aluminum, and a concrete building as shown is $F$ ig. 1. While this may not be the design chosen for the LMF, it serves as a useful example for discussing radiologica? issues, and it serves as a point of comparison for the other concepts being proposed. Where possible, we point out the articipated impact of design modifications.

Note that although aluminum is generally consldered a low-actluation material, the $24 \mathrm{Na}$ produced by $(n, a)$ reactions with 27 Al is particularly troublesome for the first few days after a shot. The $24_{\mathrm{Na}}$ has a half $l$ ife of 15 hours and its decay yields two high energy gammas (2.75 and $1.37 \mathrm{MeV}$ ).

Our analysis includes: effects of leaxage neutrons (from some 72 beam ports). materials impurities, nuclide bulldup, and neutron scattering from concrete and beam tubes. Our estimate of the 24-hour dose rate at a diagnostic platform includes contributions from the activation of air, concrete, bean tubes. vacuum chamber, and interlor chamber naterials.

Two crucial design issues are the post-shot tritium recovery and radiation damage to final optics. We incl Je data concerning the amount of tritiated vaste and discuss means of handling and disposing of it. He a iso show that, at the projected radius of 25 meters. neution damage to the final optics (degradation of transmission) will not impede (MF operations.

\section{GENERAL NEUTRONICS ISSUES}

The calculations performed for this paper were done using the computer codes TART, 5 FORIG, 6 and ORLIB. 7 The neutron-photon transport code TART uses a Monte Carlo technique to determine the spatially-and energy-dependent fluences of neutrons and photons. CRLIB combines the neutron spectra from TART with our most current neutron cross section library to produce one energy group. spatialiy averaged, neutron activation cross sections. This information is then used by the nuclide generation-depletion ccte FORIG.

Generaliy. TART was also used to determine the dose rates near activated surfaces using photon transport calculations and vater to simulate tissue, as tissue is 7 iz water. Nitrogen. oxygen-like in absorbing decay radiation. is another $23 \%$. Therefore water is an adequate model for 947 of the body.

The buildup of nuclides over time was considered in all the andiyses using the equation

$$
H=N_{n}\left[\left(1-e^{-\lambda t n}\right) /\left(1-e^{-\lambda t}\right)\right] .
$$

where $N$ is the number of curies of a given nuclide after $n$ shots spaced time units apart. $H_{0}$ is the amount of the nuclide produced on a single shot, and $\lambda$ is the decay constant for the particular nuclide. The nuclide bulldup approaches secular equilibrium

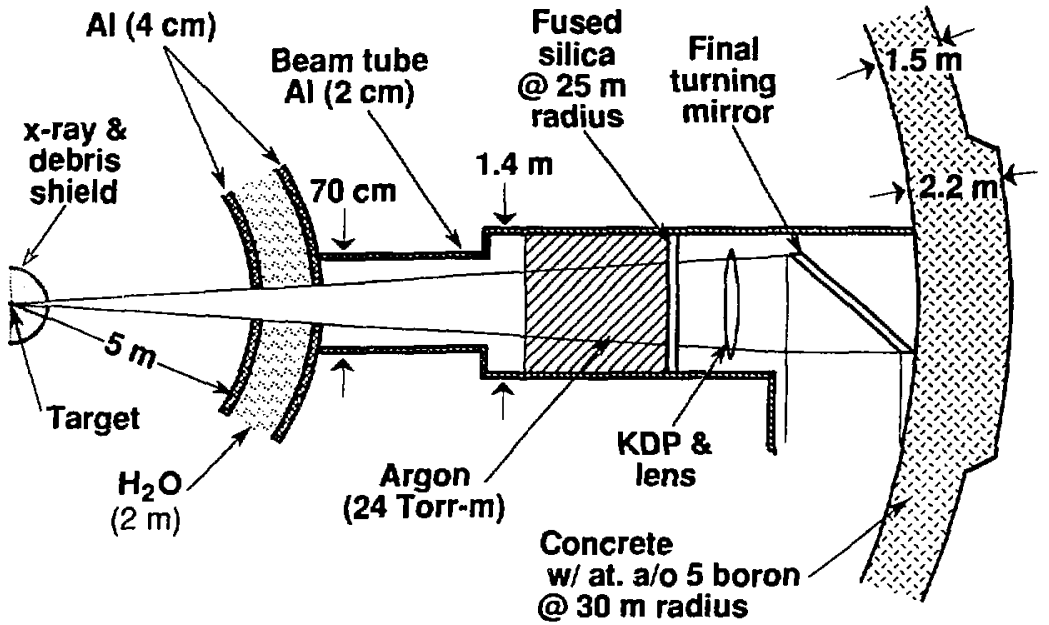

Fig. I. Final optics protection and biological shield dimensions for activation analysis. 
(where the amount that decays between shots is equal to the amount produced in a single shot). For example, at a shot rate of one per week, the buildup of $24 \mathrm{Na}$ produced in $\mathrm{Al}$ after 500 shots is 1.00043 times the quantity produced in the first shot. For $54 \mathrm{Mn}$, which is produced from $F e$ ard has a half-life of 312 days, the buildup is 64.8 times the quantity produced in the first shot.

The or of the target (the density of the fuel region times its thickness) has a moderate effect on the activation of interior-chamber and first wall materials since it changes the neutron energy spectrum due to scattering in the fuel. The greater the or of the fuel. the greater the neutron energy deposited in the fuel itself before the neutrons escape. A pr of $3 \mathrm{~g} / \mathrm{cm}^{2}$ will be the average ruel density achleved in LMF although some targets may achieve a pr of $5 \mathrm{~g} / \mathrm{cm}^{2}$. The effect of the target's or on materlal activation is expected to be greatest fur those neutron reactions with thresholds ( $1 . e$. . minimum neutron energy requiled to make the reaction energatical?y possible). For example, about 104 less 24 ara is produced in an Al first wall for a or of $5 \mathrm{~g} / \mathrm{cm}^{2}$ target than for a or of $3 \mathrm{~g} / \mathrm{cm}^{2}$ target, assuming the yie? is the same in both cases. Implications of a range of or values are beling considered in the LMF design.

\section{EXPERIMENT AREA DESIGNS}

Two issues dominate the design of the EA: how to orevent or deal with the $x$-ray ablation of the first surface, and how to imit activation levels after high-yield shots to allow adequate accessibility.

The rays will be cealt with in che or more of the following ways: with an $x$-ray and debris shleld made of $15 \mathrm{~cm}$ of solid nitrogen or $0.25 \mathrm{~cm}$ of polyethylene at a radius of $20 \mathrm{~cm}$ (Ref. B): with a water frost layer condensed on an aluminum first wall9; with a sacrificial layer at the first wall made of alumina; with a carbon-carpet inner surface; or with pyramid-iike carbon tiles. id

Linfting activation levels is done through careful material selection (high purity. low activating) and by providing adequate shielding to moderate and absorb the neutrons sufficiently to retard activation. The choice of low-activating aluminum allows re-entry into the chamber at the 7-day poinc (100 mrem/hr). For such a design, sufficient shielding must back this first Al yall to do two things: prevent activation of the second Al wail outside the shleiding and attenuate the decay radiation from the first wall. This can be accomplished with 2 of of water. (see Fig 1.)

The 15-cr-tntck $x-$ ray and debris shield made of solld nitrogen provides not only a sink for soft $x$ rays and debris but also moderates and absorbs enough neutrons through $(n, y)$ captures to reduce the activation in an aluminum first wall by about $1 / 3$ from the case with no debris shield. This reduces the time required for re-entry by haif a day. The carbon-14 and tritium production from the nitrogen is insigntficant.

Aluminum will be the material of choice over stainless steel for the frost condensing surface. Calculations using 3-m-thick paneis indicate that SS 304 would give an interior chamber ciose rate 25 times greater than Al 5083 6 days after 500 fuli-yield sho:'s (one-weet. spacing). This Al 5083 dose rate ( $40 \mathrm{mrem} / \mathrm{hr}$ ) could be cut in half if a low-activation Al with similar properties to Al 5083 were used. The constituents of this low-activation aluminum are listed in Table I (Ref. 11).

The frost concept currently includes the idea of using fiberglass (located behind the aiuminum condensing surface) as the vacuum vessel and as the container of the water used as the main neutron shield. The cholce of fiberglass would result in an extrenely low residual level of activation. Access to both the outer wall and the interlor would be much less inhibited than with any other scheme proposed thus far. Detailed analysis of the performance of fiberglass in a radtation field is necessary. However, epoxy phenolics can generally withstand about $10^{g}$ rad before experiencing signiflcant weakening. 12 A $5-\mathrm{cm}$ first wall of fiberglass would recelve on the order of that dose during the LHF lifetime.

Proponents of the carbon-carpet first wall concept have also proposed using a Kevlar epoxy first wall, thus eliminating most of the Al (except for some support structures) from the high energy fiux. This tco would result in very low activation and good access to the interior of the chamber.

\section{ACTIVATION OF ARGON GAS USED IO PROTECT FINAL OPTICS}

Final optics must be protected from $x$ rays and debris as well as shrapnel. Shown in fig. I is

Table i. Aluninum alloy with propertles similar to Al 5083 but with lower impurity and activation levels. 11

$$
\begin{aligned}
& 94.999 w 12 \\
& 4.5 \\
& 0.5 \\
& 0.001
\end{aligned}
$$$$
\text { Al }
$$$$
\mathrm{Hg}
$$$$
\text { 5⿺ }
$$ 
a conceptual design of such a protection system. 13 of interest for neutronics analysis is the 24 Torrem of argon intended to protect the fused-slitica from soft $x$ rays. A potential concern is the production of 41 ar, both in the beam tube and in the surrounding ambient ajr, by the leakage neutrons. The concentrations of $41_{A r}$ in and out of the beam tubes were calculated. The

41 ar concentration in a beam tube after a shot is at most $4 \times 10^{-3} \mathrm{Ci} / \mathrm{m}^{3}$. Although this exceeds the allowable concentration for continusus exposure to workers, the concentration decays to $4.5 \times 10^{-7} \mathrm{Cl} / \mathrm{m}^{3}$. at the 24-hour re-entry point, about an order of magnitude less than the allowable limit. Likewise, the concentration in the ambient air of the target chamber (due to the activation of the argon in the air) is $5 \times 10^{-5} \mathrm{Cj} / \mathrm{m}^{3}$ after shot and $6 \times 10^{-9} \mathrm{Ci} / \mathrm{m}^{3}$ at the 24-hour point.

\section{ACTIVATIOH OF BEAM TUBES}

The activation of the aluminum beam tubes is also a major concern that could prevent re-entry into the EA within 24 hours aiter a maximuin yield shot. Estimated to be $2 \mathrm{~cm}$ thick. the tubes are modeled as cylindrical tubes encasing each final focusing optic at the concrete wall and extending to the discrete port for beam entry at the chamber outer wall. This design, a cylindried instead of tapered cone tube, uses the overlap around the actual beam hole as a shadow shield that effectively protects the beam tube from direct-shine neutrons. The actual beam hole at the chamber outer wall may be only $50 \mathrm{~cm}$ in diameter. The tube diameter is $1.4 \mathrm{~m}$ at the final optic. changing to $0.7 \mathrm{~m}$ at the second wall (see Fig. 1). The smaller radius is required at the chamber wall to provide adequate spacing for all 36 bean tubes in the desigrated solid angle of the sphere. Caliulations indicate that the dose rate from the aluminum lube 24 hours after the five hundredth $1000-M J$ shot is only $1.2 \mathrm{mrem} / \mathrm{hr}$. A further step to minfmize bean tube activation would be to line the interior of the tube with a thin layer (1 cm) of $\mathrm{CH}_{2}$. It is expected that those neutrons with a near grazing incidence to the beas tube material will see an effective thickness of moderator that will serve to further reduce neutrons to energies below the threshold for the $\{n, \ldots)$ reaction in Al tinat nets the troublesome nuclide. 24Ha. Further work is required to establish the merit of this proposal and to see if normal Al 5083 could be used.

\section{NEUTRON OAKAGE TO FINAL OPIICS}

Find focusing lenses should be made of a material that is resistant to radiation damage and produces insignificant residual radiation. The leading material of cholce is fusedsillica. We have conducted a study of the effects of 1a-HeV neutrons in fused-silica when exposed to fluences that are predicted for the LMF final focusing lenses, wich are currently set at 25 in from the target. The experimental fiuence was $1.5 \times 10^{16}$ neutrons $/ \mathrm{cm}^{2}$.

$\pm 20 \%$. This is equivalent to -3300 fullyleld shots. This far exceeds the projected number of full-yield shots for the LHF lifetime covering high-gain developnent $(100$ full-yiald shots). weapons physics experiments

( 1000 full-yield shots), and weapons effects experiments (100 full-yield shots). Including moderate- and low-yield shots, the equivalent number of lifetime full-yield shots will be $1600(\operatorname{Re} f$. i4).

In this more recent experiment. a sample of fused-stilica, $2.7 \mathrm{~cm}$ in dianeter and $-1 \mathrm{~cm}$ thick, was irradiated using the Rotating Target Neutron Source (RTNS II) facllity over a tro-week period in Hay 1987. Spectrophotometry measurements akde before and after the exposure indlcated a change in optical density primarfly below $400 \mathrm{~nm}$ with the peak at $215 \mathrm{~nm}$. The baseline transmittance at $3 \omega(1.06-\mu m$ wavelength light) and $2 \omega(0.53 \mu \mathrm{m})$ was not altered. However, there was some degradation at $3 \omega(0.33 \mu \mathrm{m})$ and substantial reduction in transmittance at $4 \mathrm{w}(0.26 \mu \mathrm{n})$. An earlier study showed no degradation in transwission at any wavelength for an experimental fluence level of $1.5 \times 10^{15}$ neutrons $/ \mathrm{cm}^{2}$. The final optical density measurenents as a functior of wavelength are given in Fig. 2 .

The neutron-induced effects vere largely reverstble. Annealing of the sample at $400^{\circ} \mathrm{C}$ for two hours significantly recovered the transmittance. An additional 4-hour annealing had significantiy less impact. suggesting a much longer required time to completely reverse the effects. Gamma spectrometry analys is Indicated that there is a srall amount of impurttles in fused-silica, namely, $2 n$, Mn, íe, Ha, and $Y$. However, the resultant activation made ro significant contribution to the residual radiation levels.

The degradation in transaission is assumed to be due to atomic displacements by neutrons. However, 5.57 of the total dose (1 Mrad out of 15.7 Mrad) to the sillica is from secondary gama radiation. There are indications that the gamia radiation threshold for damage is greater than 10 Mrad (Ref. 15). The degree to which electronic collisions may be reducing transmission will be explored later when a sample will be exposed to a comparable gama dose and rore spectrophotometry messurements are made.

\section{A]R ACTIVATION}

The activation of the ambient air in the concrete enclosed dome mist not prevent access to the chamber at the 24-hour point for a full-yield shot. Calculations indicate that, a 
day after a $1000 \mathrm{MJ}$ shot a 30-m-radius dome will contain $0.1 \mu \mathrm{Ci}$ of $4 \mathrm{l}_{\text {Ar }}$ produced from the neutrons that get through the 2-m-thick shield. The contribution from the direct shine neutrons that escape through the 2 to $3 \mathrm{~h}$ open solid angle and scatter of the concrett is $60 \mathrm{mCl}$ of $\mathrm{A}_{\mathrm{A}}$ at this same time. The Derived Air Concentration (the allowable concentration for someone to continualiy breathe and not receive more than 5 rem in one yearl is $3 \times 10^{-6} \mathrm{Ci} / \mathrm{m}^{3}$ and is an order of magnitude greater than the actual concentration at 24 hours.

\section{BIOLOGICAL SHIELO}

Personnel must be protected from receiving excessive p-ompt dcses of radiation from a high-yield shot. as well as from the restdual radiation. Our results indicate that a 1.5-m-thick concrete wall enclosing the paperimental area $\forall i l l$ reduce the prompt exposur:- immediately outside the EA bullding to less than 1 mrem/shot, or $50 \mathrm{mrem} / \mathrm{yr}, 12$ of the allowabie annual dose. An additional 0.7 m of concrete (2.2 m tatal) will be required behind the final optics at the end of the beam ports (see Fig. I).

The activation of the concrete presents a source of residual radiation that might constrafir access to the diagnostic ports at the 24-hour point. The 72 beam tubes constitute clear paths for unmoderated neutrons to create "hot spots" in the concrete wall. Assuming that the inner radius of the concrete is 30 meters, the dose at the 7-m diagnostic ports at 24 hours is estimated to be about $10 \mathrm{mrem} / \mathrm{hr}$. The overwheluing contribution to this dose rate is $24 \mathrm{Na}$ proutction from $(n, \gamma)$ reactions with $23 \mathrm{Na}$ in the concrete. The addition of boron to the concrete to suppress this reaction will be required, as well as some inelastic scattering shielding in front of or imbedded in the concrete. Adding 5 at. $z$ boron to the concrete is estiatated to reduce the activation by an order of magnitude. Further work is ahead to tailor the concrete shield to the specific LMF needs. He may also consider the use of "moblle shielding" to shield the diagnostic platforms from the concrete.

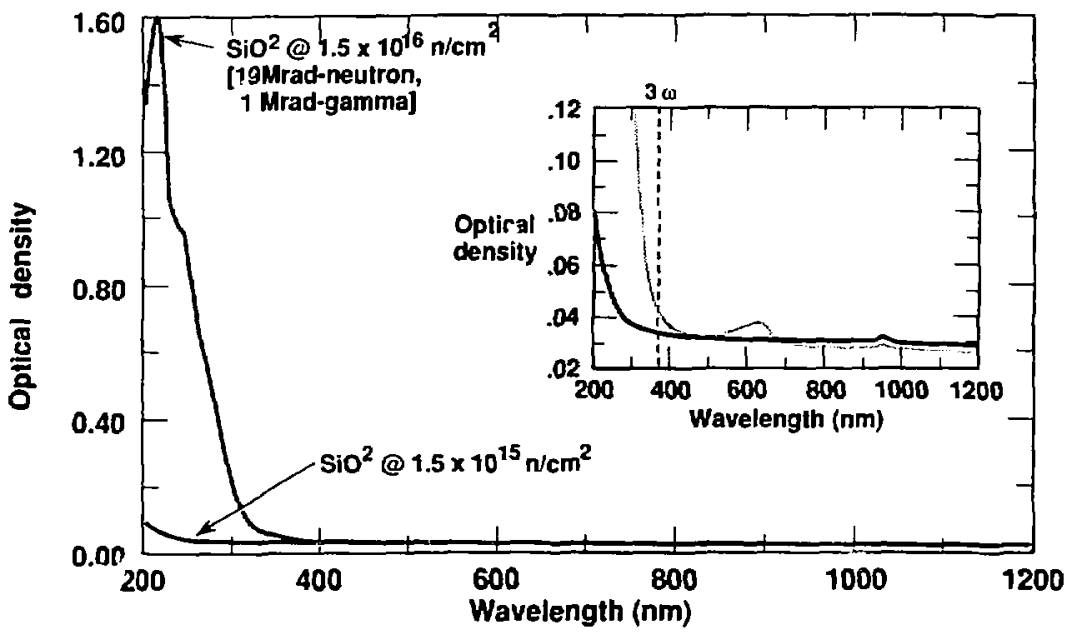

Final optics are set at $25 \mathrm{~m}$ from the larget Transmission $(T)=10-0, D$ is optical density

fig. 2. Heutrons and neutron-induced ganma rays cause insignificant transmission loss at 3 in fused-silica for proposed LMF lifetime fluences $\left(7 \times 10^{15} \mathrm{n} / \mathrm{cm}^{2}\right)$. 
NEUTRCN HEATIRG CLOSE TO THE TARGET

He made a number of neutronics calculations to determine the neutron heating in materials positioned close to the target. These might include target-support structures, shrouds, irradiation samples, and perhaps even diagnostics. Calculations were done for $A$ l, Fe, $\mathrm{Cu}$, and $\mathrm{SiC}$.

Dur results show that all the materials wll melt, sublime, or dissociate if placed within 10 to $20 \mathrm{~cm}$ of a $1000-M J-y i e l d$ target. Carbon and silicon carbide have comparable mintmum inner radif at about $13 \mathrm{~cm}$, while the three metals considered have minimum radii closer to $20 \mathrm{~cm}$. Steel is slightly better than A) and $\mathrm{Cu}$. Even if we can protect materials from $x$ rays and debris, anything this close to the target must be considered sacriflcial since it 111 be destroyed by neutron heating. The innermost 10 to 20 in of the target support structure, for example, will have to be replaced for every shot.

\section{INTERIOR DOSE RATE}

The cumulative interior dose rate goal is $<100$ mremihr about seven days after a full-yield shot. The contributions to this dose rate come from the following: the target shroud and support mechanism, the ablatert and recondensed first wall, the remaining tritium (internal dose), the sacrificial diagnostics. the first wall, and any materials introduced into the chamber as part of an experiment (e.g.. military applications). The tritium will be rapidly pumped from the chamber within minutes. depending on the first wall construction. The target support components wil be constructed from composite aterials such as carbon-carbon or Kevlar to avold the activation problem here. Sacriffcial diagrostics wili also be made of nonactluating materials. The first wall, if solid nitrogen. will not present any significant radiological hazard, no: $\forall i l l$ polyethylene or frost. The carbon will not haye Dersistent activation profucts, as long as it is kept pure. A first wall. made of $4 \mathrm{~cm}$ of low activating Al (see Table is at a 5-m radius, will give $100 \mathrm{nrem} / \mathrm{hr}$ about seven days after five hundred $1000 \mathrm{MJ}$ shots spaced one we ak apart, when the solld nitrogen shieid is used (and a value one-third higher when it is not). For a 3-m-radius first wall . 2-cm thick). $100 \mathrm{mrem} / \mathrm{hr}$ is attained at 7.5 days after the five-hundredth 1000-HJ shot. The longer time is requirea due to $1 / r^{2}$ ffects and the less self-attinuation of decay ganma rays in the thinner aluminum wail Therefore, feel that d dose rate of 100 mren/hr at about the seven-day point is attainable. This rate will allow limited personnel access Into the chamber at thls time.

\section{EXTERIOR DOSE RATE}

Contributions to the exterior dose rate are: the first wall decay, the second wall decay. decav of impurities in the water that are ac: rated, the concrete, and the bean tubes. As mentioned earlier, the dose rate from the first wall (5-m radius) outside the second wall (after 2 m of water) is $1 \mathrm{mrem} / \mathrm{hr}$. The dose rate at this same point from the activated concrete (due to "through-the-shield" neutrons) is only $3 \mu \mathrm{rem} / \mathrm{hr}$. However, the "hot spots" created by tne direct shine (leakage) neutrons will contribute $-1 \mathrm{mrem} / \mathrm{hr}$ for a 5 at.$z$ boron concentration in the concrete backing the final optics. Our water shieid is not borated, both because a saturated solution of boracic acid in the water (the simplest way to borate the water) does not introduce enough boron in the water to make a significant difference and because the boracic acid or other boran compounds would introduce jmpurities into the water, rost notably sodfum. The contribution from activated bean tubes to the overall dose rate at the equator of the sphere is less than $0.1 \mathrm{mrem} / \mathrm{hr}$. Since the goal is to linit the exterior dose rate to $-2 \mathrm{mrem} / \mathrm{hr}$, a conceptua? design with the features listed above can feasibly achieve the goal dose rate.

\section{WASTE HANDLING}

The expected tritium (liquid ( $<5 \mathrm{mCi} / \mathrm{yr}$ ) and gaseous ( $100 \mathrm{Ci} / \mathrm{yr}) \mathrm{l}$ effluents at il be many orders of magnitide below the maximum permissible concentrations and total quantities as given in DOE 5480.11. The design objective - is to jimit the facility's controlied releases to s100 Ci/yr. This value was easily met by the RTNS II facility, which had a somewhat higher tritium throughput. A typical high gain target will contain 10 to $50 \mathrm{mg}$ of tritium. An estimated annual throughput then is $25,000 \mathrm{Cl}$. For an aluminum first wall. the restdual tritiun offfusing from the wall after the chamber is pumped out will not present a personnel hazard. For a frost first wall, the Sulzer process for tritiun cecovery would be used. 36 This can involve cryogenic distillation, combined electrolys/s catalytic exchange (CECE), water distillation. electrolysis, grttering. gas storage, and fixation. Here, the tritium could be recyc?ed as it is currently worth $\$ 20,000$ per gran. The Sulzer process increases the tritium concentration in one stream while greatly reducing (by up to six orders of magnt tude) the concentration in the other stream. After 20 years operation, the total volume for the highly concentrated tritiated water could be oniy 300 liters. Since this water can be easily doubly contained in certified staliniess steel vessels. it presents no significant hazard. Any discharges will be many 
orders-of-magnitude below the pertinent standards. At concentrations $>1000 \mathrm{Ci}$ per container, the waste must be handled as Class $B$, with the appropriate containers. etc. We estimate the total cost for waste disposal for the first ten years of operation to be roughly $\$ 2 M$. By keeping the site tritium inventory to $<30 \mathrm{~g}$ could ease siting requirements.

\section{COHCLUSIOHS}

Fac!lity and experimental goals for the LMF can be achieved through carefui design of the experimental area. Our calculations show that careful design and material selection can minimize activation and that sufficient shielding can be employed to protect materials prone to activation. For a rhamber that uses an Al first wall, 24 Na produced by $(n, \alpha)$ reactions tith $27_{A}$ is is the design-limting radiological hazard. In the case we examined, a 2-m-thick water shield was nepded to reduce the dose rate at the diagnostic platform at the 24-hour point to an acceptable level. Reducing the amount of $A$ ? (or eliminating it) from the high energy flux would reduce the shielding requirements and allow earlier access to the inside of the chamber. Interestingly, 24 pa produced by $(n, y)$ reactions with $23 \mathrm{pa}$ in the concrete wall: of the experiment area also present some difficulties. This radiation hazard can be reduced by adding boron to the concrete. Neutron damage to final optics appears to be manageable and the effects of neutrons leaking through beam ports can be mitigated. The waste produced by the facility. predominantly tritium. can be safely and economically managed.

\section{ACF.NOWL EDGMENT}

This work was performed under the auspices of the U.S. OOE by the Lawrence Livermore National Laboratory under contract No. H-7405-ENG-48.

\section{REF ERENCES}

1. "General Design Criteria Manual," U.S. DOE, DOE Order 6430. iA (DeC. 7, 1987).

2. "Princigles for Limiting Exposure of the Public to Natural Sources of Raciation," International Commission of Radiological Protection, Pub. 39. Ann. of ICRP (1983).

3. "Radiation Protection for Occupational Workers," U.S. DOE, DOE Order 5480.11 (draft 4/5/88; effective Jan. 1, 1989).

4. "LLML ALARA Program," Health and Safety Manual Supplement 33.011, Lawrence i ivermore National Laboratory (1986).
5. E. F. PLECHATY and J. R. KIHLINGER, "TARTMP: A Coupled Neutron-Photon Monte Carlo Transport Code." UCRL-50400 Vol. 14, Laurence Livermore Nationa] Laboratory (1976).

6. J. A. BLIN. "FORIG: A Computer cose for Caiculating Radionuclide Generation and Depletion in Fusion and Fission Reactors." UCRL-53633. Lawrence Livermore Mational Laboratory (1985).

7. J. A. BLINK, R. E. DYE, and J. R. KIMLIHGER. "ORLIB: A Computer Code that froduces One-Energy Group. Time- and SpatiallyAveraged Heutron Cross Sections." UCRL-53262, Lawrence Li reraore National Laboratory (1981).

8. J. H. PITTS et al.. "Preventing Vaporization and Destructive Shock Haves in ICF TargetChamber First Walis." these proceedings.

9. C. D. ORTH, "Frost as a First Hall for the ICF Laboratory Microfusion Facility." these proceedings.

10. M. J. MONSLER and $W$. R. MEIER, "A CarbonFiber Brush-Like First Wall for the Laboratory Microfusion Facility." these proceedings.

11. J. H. PITTS and P. R. LAHDOH, Lawrence Livermore National Laboratory,private communication (1988).

12. A. E. PROFIO, Radiation Shielding and Dosimetry. John Wiley and Sons. Ine. New York. NY (1979).

13. D. G. NILSON and J. G. HCODWORTH, "Final Optic Protection Designs for IC,F Containment Chambers." these proceedings.

14. H. T. TOBIN, et al., "BOE Requirements for the LMF Experiment Area," Laser Prostan Annual Report 87 . UCRL-50021-97, Lawence Livermore kat onal Laboratory, to be published.

15. L. G. DESHAZER, L. E. GORRE and R. C. PASTOR. "Water Free Fused Silica for Laser Windows Made by the Reactive Atmosphere Process," 3 . Non-Cryst. Solids 82._189 (1986).

16. C. Bo00y, Sulzer Canada, Inc., Toronto, Canada, private communication (June 1988). 